\title{
Influência da temperatura sobre a longevidade, fecundidade e atividade hematofágica de Aedes (Stegomyia) albopictus Skuse, 1894 (Diptera, Culicidae) sob condições de laboratório ${ }^{1}$
}

\author{
Daniéla C. Calado \\ Mario Antonio Navarro-Silva ${ }^{3}$
}

\begin{abstract}
Influence of temperature on longevity, fecundity, and haematophagic activity of Aedes (Stegomyia) albopictus Skuse, 1894 (Diptera, Culicidae) under laboratory condition. Based on adults of Aedes albopictus maintained under four constant temperatures, $15^{\circ} \mathrm{C}, 20^{\circ} \mathrm{C}, 25^{\circ} \mathrm{C}$ and $30^{\circ} \mathrm{C}$, longevity of males and females, fecundity, eggs viability, number of days from emergence to the first bloodsucking, and duration of the preoviposition period were observed. The average of the longevity for female was $19.45,59.35,61.55$ and 42.72 days, under $15^{\circ} \mathrm{C}, 20^{\circ} \mathrm{C}, 25^{\circ} \mathrm{C}$ and $30^{\circ} \mathrm{C}$, respectively. The greatest average number of bloodsucking per female was 8.32 , under $25^{\circ} \mathrm{C}$. The average number of eggs per female was $1.00,73.91$, 269.87 and 183.69 , and the greatest rates of viable eggs per female was $25^{\circ} \mathrm{C}$ and $30^{\circ} \mathrm{C}$. The haematophagic activities and the oviposition were significantly influenced by temperature.
\end{abstract}

Keywords. Aedes albopictus; biology; fecundity; longevity; temperature.

\section{INTRODUÇÃO}

Aedes (Stegomyia) albopictus Skuse, 1894, é originária do sudeste da Ásia e apresenta ampla distribuição geográfica. O primeiro registro desta espécie no Brasil é de ForatTiNI (1986), no Estado do Rio de Janeiro. Desde então, outros encontros foram relatados para vários estados brasileiros, abrangendo as áreas rural, suburbana e urbana (Gomes et al., 1992).

Esta espécie é incriminada como vetora de Dirofilaria immitis (Leidy, 1856) no Japão (Konishi 1989) e de múltiplos arbovírus, como o da encefalite tipo leste, nos EUA (MitchelL et al. 1992). Para o continente americano, IBAÑEZ-BERNAL et al. (1997) relataram o primeiro encontro de Aedes albopictus naturalmente infectado com o vírus da dengue.

Segundo Sullivan et al. (1971), na Tailândia, esta espécie é capaz de alimentar-se em uma variedade de animais, sendo mais atraída pelo homem que por iscas bubalina, suína, canina ou por aves. LABARTHE et al. (1998), na cidade de Niterói (Estado do Rio de Janeiro), também verificaram que as fêmeas desta espécie são mais atraídas em isca humana que em iscas felina ou canina. Entretanto, Marques \& Gomes (1997), como conseqüência da análise dos dados de estudo do comportamento antropofílico de Aedes albopictus na região do Vale do Paraíba, sugerem contato oportunista entre Aedes albopictus e o homem, do qual se deduziria maior dificuldade para circulação do vírus da dengue entre humanos em áreas por ele infestadas. Contudo, a facilidade em explorar áreas rurais, urbanas e de floresta, pode facilitar os ciclos urbanos de febre amarela na América do Sul, pela ligação dos ambientes de floresta e urbano (RAI 1991).

Apesar de sua importância epidemiológica, no Brasil, pouca informação tem sido gerada até o momento quanto à longevidade, fertilidade e fecundidade de Aedes albopictus, sob condições de laboratório, principalmente em relação ao efeito da temperatura. Diante da facilidade de dispersão e ocupação de novos ambientes apresentada por Aedes albopictus, torna-se necessário o conhecimento de como esta espécie exótica desenvolve-se sob diferentes regimes de temperatura. Isto possibilitará melhor entendimento de sua biologia e o levantamento de maior número de informações que poderão ser utilizadas em programas e estratégias de controle.

Diante destas considerações, este trabalho teve como objetivo verificar a influência da temperatura sobre a hematofagia, oviposição e longevidade de Aedes albopictus, sob condições de laboratório, em quatro temperaturas constantes e fotoperíodo de CE 12:12 horas.

1. Contribuição $n^{\circ} 1334$ do Departamento de Zoologia da Universidade Federal do Paraná. Financiamento: PEAa (FNS, Ministério da Saúde, OPAS).

2. Curso de Pós-Graduação em Entomologia, Departamento de Zoologia, Universidade Federal do Paraná. Curitiba - PR, Brasil. Bolsista do CNPq. Endereço eletrônico: dcalado@bio.ufpr.br.

3. Laboratório de Entomologia Médica e Veterinária, Departamento de Zoologia, Universidade Federal do Paraná. Caixa Postal 19020, 81531-990 Curitiba - PR, Brasil. Endereço eletrônico: mnavarro@bio.ufpr.br 


\section{MATERIALEMÉTODOS}

O estudo da influência de temperaturas constantes sobre a longevidade, fecundidade e atividade hematofágica de Aedes albopictus foi desenvolvido sob condições de laboratório, a partir de colônias originárias de imaturos coletados em área urbana da cidade de Registro (Vale do Ribeira, Estado de São Paulo, Brasil), em março de 1999. Desde então, colônias desta espécie são mantidas no insetário do Laboratório de Entomologia Médica e Veterinária do Departamento de Zoologia da Universidade Federal do Paraná, sob temperatura de aproximadamente $25^{\circ} \mathrm{C}$ e fotoperíodo natural.

Os experimentos foram conduzidos sob quatro temperaturas constantes, $15^{\circ} \mathrm{C}, 20^{\circ} \mathrm{C}, 25^{\circ} \mathrm{C}$ e $30^{\circ} \mathrm{C}$, em câmara climatizada modelo 347 marca FANEM, fotoperíodo CE 12:12 horas e umidade relativa entre 70-85\%. A partir dos espécimens adultos mantidos nas diferentes temperaturas, foram realizadas observações quanto à longevidade de machos e fêmeas, fecundidade, viabilidade dos ovos, tempo transcorrido entre a emergência e o primeiro repasto sanguíneo, e duração do período de pré-oviposição.

Quarenta indivíduos fêmeas e oitenta machos foram utilizados neste experimento. Indivíduos adultos recémemergidos, dois machos e uma fêmea, foram colocados em recipientes de PVC com $7,5 \mathrm{~cm}$ de diâmetro e $10 \mathrm{~cm}$ de altura. A extremidade inferior do recipiente foi mantida fechada por tela de nylon com malha de $1 \mathrm{~mm}$ e a superior, por filme plástico. Estes recipientes apresentavam uma abertura circular lateral de aproximadamente $1,5 \mathrm{~cm}$ de diâmetro, pela qual foram oferecidos a alimentação açucarada e o repasto sanguíneo em hospedeiro humano. Alimentação sanguínea foi ofertada diariamente, um dia após ao da emergência das fêmeas, durante cinco minutos. A alimentação açucarada foi fornecida em chumaço de algodão embebido em solução de mel a $10 \%$, sendo substituída diariamente para evitar a proliferação de fungos.

Para obtenção das posturas foram introduzidos frascos com aproximadamente $3 \mathrm{~cm}$ de diâmetro e $3 \mathrm{~cm}$ de altura, contendo chumaço de algodão embebido em água de torneira e cobertos por papel filtro. Uma vez ao dia, os frascos foram monitorados para a coleta e contagem de posturas. As posturas obtidas foram individualizadas em recipientes de $50 \mathrm{ml}$ contendo água de torneira submetida à areação por 24 horas e alimento (ração para peixes Tetramin ${ }^{\circledR}$ ), sendo identificadas com o número da fêmea e a data de postura. A cada dois dias, as posturas foram monitoradas para a contagem e retirada de ovos viáveis. As posturas foram monitoradas por um período mínimo de três meses.

Através da análise de variância e do teste de Tukey-Kramer ao nível de $5 \%$ foram testados os efeitos de quatro temperaturas sobre as variáveis biológicas: a) número total de repastos por fêmea; b) período entre a emergência e o primeiro repasto sanguíneo; c) número total de ovos por fêmea; d) número de ovos/dia/fêmea; e) número de ovos/repasto/fêmea; f) período de pré-oviposição; g) longevidade de machos; h) longevidade de fêmeas.

Exemplares de Aedes albopictus foram depositados na Coleção de Entomologia Pe. Jesus Santiago Moure (DZUP), do Departamento de Zoologia, Universidade Federal do Paraná.

\section{RESULTADOSEDISCUSSÃO}

Em todas as temperaturas testadas foi possível a manutenção das formas adultas de A. albopictus, entretanto os menores períodos médios de vida foram observados nos extremos de temperatura, $15^{\circ} \mathrm{Ce} 30^{\circ} \mathrm{C}$. As fêmeas apresentaram longevidade aproximadamente 1.5 vezes maior que os machos. (Tabela I). A longevidade média observada a $25^{\circ} \mathrm{C}$, tanto em machos quanto em fêmeas, foi superior à detectada por GUBLER $\&$ Bhattacharya (1971) a $26^{\circ} \mathrm{C}$; neste caso o período médio para machos e fêmeas alcançou 30.3 e 38.0 dias, com a longevidade máxima atingindo 68 e 73 dias, respectivamente.

As temperaturas de $20^{\circ} \mathrm{Ce} 25^{\circ} \mathrm{C}$, tiveram efeitos semelhantes sobre a sobrevivência dos adultos. A $15^{\circ} \mathrm{C}$, o número de sobreviventes diminuiu sensivelmente nas primeiras idades,

Tabela I. Longevidade média, mínima e máxima de fêmeas e machos de Aedes albopictus, sob quatro temperaturas constantes, $15^{\circ} \mathrm{C}, 20^{\circ} \mathrm{C}, 25^{\circ} \mathrm{C}$ e $30^{\circ} \mathrm{C}$, fotoperíodo de CE 12:12 horas e umidade relativa de $70-85 \%$.

\begin{tabular}{|c|c|c|c|c|c|c|}
\hline \multirow{2}{*}{$\begin{array}{l}\text { Temperatura } \\
\left({ }^{\circ} \mathrm{C}\right)\end{array}$} & \multicolumn{3}{|c|}{ Longevidade de Fêmeas (dias) } & \multicolumn{3}{|c|}{ Longevidade de Machos (dias) } \\
\hline & Média (D.P.) & Mín. & Máx. & Média & Mín. & Máx. \\
\hline $15^{\circ} \mathrm{C}$ & $19,45(11,11) \mathrm{aA}$ & 2 & 48 & $13,60(8,99) \mathrm{aB}$ & 1 & 51 \\
\hline $20^{\circ} \mathrm{C}$ & $59,35(27,44) \mathrm{bA}$ & 4 & 136 & $38,29(21,65) \mathrm{bB}$ & 2 & 89 \\
\hline $25^{\circ} \mathrm{C}$ & $61,55(22,57) \mathrm{bA}$ & 10 & 114 & $42,32(19,87) b B$ & 3 & 92 \\
\hline $30^{\circ} \mathrm{C}$ & $40,72(21,80) \mathrm{cA}$ & 5 & 78 & $21,49(20,11) \mathrm{cB}$ & 3 & 68 \\
\hline
\end{tabular}

Médias seguidas por letras distintas diferem entre si pelo teste de Tukey-Kramer $(p<0.05)$

Letras minúsculas comparação entre linhas e letras maiúsculas comparação entre colunas.

Número de machos por temperatura: 79

Número de fêmeas por temperatura: 40

D.P.: Desvio Padrão 

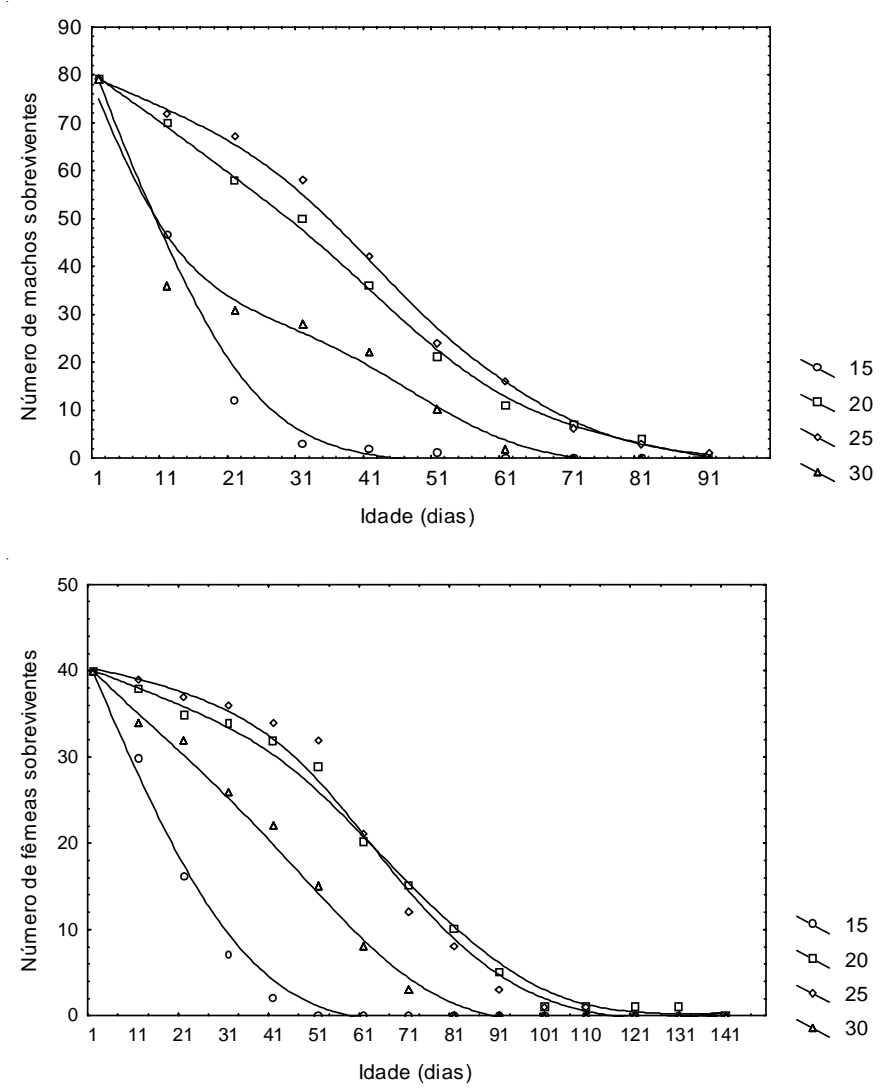

Fig. 1. Curvas de sobrevivência de machos (A) e fêmeas (B) de Aedes albopictus, sob quatro temperaturas constantes, $15^{\circ} \mathrm{C}, 20^{\circ} \mathrm{C}, 25^{\circ} \mathrm{C}$ e $30^{\circ} \mathrm{C}$, fotoperíodo de CE 12:12 horas e umidade relativa de $70-85 \%$.

indicando que esta temperatura influencia de forma negativa a longevidade dos indivíduos. A $30^{\circ} \mathrm{C}$, a sobrevivência dos machos, sofreu redução mais intensa nos primeiros dias, o que pode ter determinado redução na longevidade máxima destes (Fig.1).

Além da temperatura, a umidade relativa do ar pode ser considerada outro fator importante na determinação da longevidade dos adultos. Em observações preliminares para a determinação das condições experimentais a serem utilizadas neste estudo, observou-se que os indivíduos sobreviviam por períodos de 1 até 3 dias quando mantidos em umidade igual ou inferior a 50\%. Em campo, SLlva \& Neves (1989) verificaram que os adultos de A. albopictus são mais abundantes durante meses mais úmidos.

A temperatura afetou de forma significativa o número médio de repastos realizados por fêmea, sendo observada elevada frequência de atividade hematofágica a $25^{\circ} \mathrm{C}$, enquanto a $15^{\circ} \mathrm{C}$ as fêmeas apresentaram dificuldade para perfurar os tecidos do hospedeiro. As fêmeas eram atraídas, tateavam o hospedeiro com a probóscide, mas não posicionavam corretamente o aparato bucal. Normalmente, quando do ato da picada, o conjunto de estiletes maxilares e mandibulares penetra nos tecidos devido, principalmente, à ação perfurante e cortante das maxilas. Nesse processo, o lábio permanece fora e sua flexibilidade possibilita-lhe dobrar-se e formar ângulo com o vértice dirigido para trás (Forattini 1996). Nas fêmeas observadas, o lábio assumia posição contrária a acima descrita, sendo flexionado para a frente, o que provavelmente determinou a reduzida frequência de repasto sanguíneo observado a $15^{\circ} \mathrm{C}$ (Tabela II). Relação positiva entre temperatura e atividade hematofágica também foi observada em campo por LABARTHE et al. (1998) e MARQUES \& GOMES (1997), indicando que a maior abundância de fêmeas ocorre nos meses quentes, com frequência esporádica no período do inverno.

O tempo transcorrido entre a emergência do adulto e a realização do primeiro repasto também foi influenciado pela temperatura, sendo inversamente proporcional a esta variável (Fig. 2). As diferenças observadas entre temperaturas podem estar relacionadas ao tempo gasto para a completa esclerotinização das peças bucais, onde os períodos mais longos correspondem às temperaturas mais baixas. Nas temperaturas de $25^{\circ} \mathrm{Ce} 30^{\circ} \mathrm{C}$, algumas fêmeas foram capazes de realizar o repasto no dia seguinte ao da emergência, entretanto a maioria delas o fez entre o segundo e o quarto dia. Quando mantidas a $26^{\circ} \mathrm{C}$, GUBLER \& BHATTACHARYA (1971) verificaram que as fêmeas realizavam o primeiro repasto no segundo dia após a emergência. Intervalo de tempo semelhante foi obtido por MORI \& WADA (1977), porém sob condições de campo com temperatura oscilando entre 18,4 e $25,8^{\circ} \mathrm{C}$.

Tabela II. Número total, médio, mínimo e máximo de repastos sanguíneos, em hospedeiro humano, consumidos por fêmeas de Aedes albopictus mantidas sob $15^{\circ} \mathrm{C}, 20^{\circ} \mathrm{C}, 25^{\circ} \mathrm{C}$ e $30^{\circ} \mathrm{C}$, fotoperíodo de $\mathrm{CE} 12: 12$ horas e umidade relativa de $70-85 \%$.

\begin{tabular}{|c|c|c|c|c|c|}
\hline \multirow[b]{2}{*}{ Temperatura $\left({ }^{\circ} \mathrm{C}\right)$} & \multicolumn{5}{|c|}{ Número de repastos } \\
\hline & Fêmeas (n) & Total * & Média (D. P.) & Mín. & Máx. \\
\hline $15^{\circ} \mathrm{C}$ & 06 & 10 & $1,66(0,81)^{* *}$ & 1 & 3 \\
\hline $20^{\circ} \mathrm{C}$ & 38 & 123 & $3,23(2,55) \mathrm{a}$ & 1 & 11 \\
\hline $25^{\circ} \mathrm{C}$ & 40 & 333 & $8,32(5,33) b$ & 1 & 26 \\
\hline $30^{\circ} \mathrm{C}$ & 37 & 243 & $6,57(4,43) b$ & 1 & 21 \\
\hline
\end{tabular}

*número total de repastos consumidos em cada temperatura

** dados excluídos da análise de variância

Média seguidas por letras distintas diferem entre si pelo teste de Tukey- Kramer $(\mathrm{p}<0.05)$

D.P. Desvio Padrão 


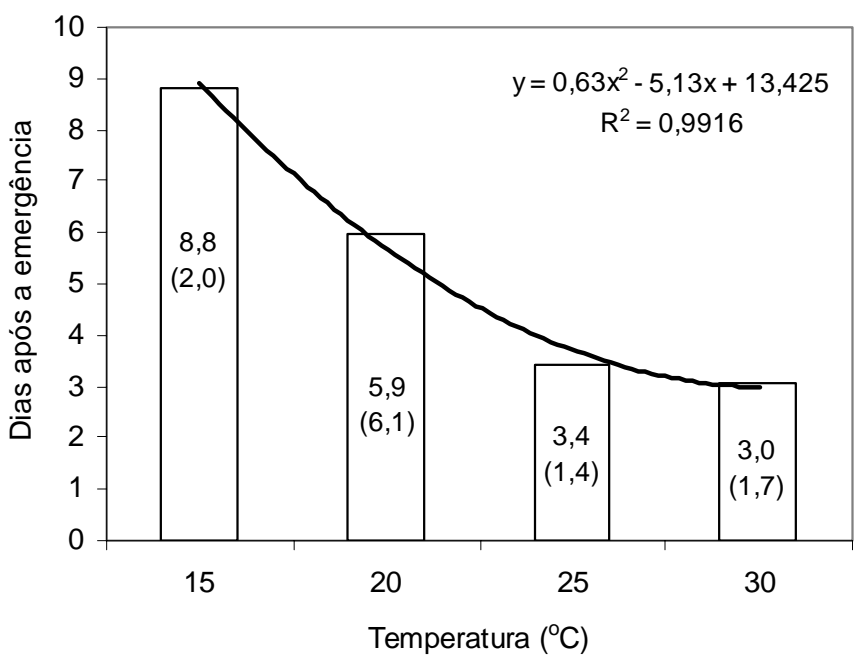

Fig. 2. Médias em dias do período entre a emergência e o primeiro repasto sanguíneo de Aedes albopictus, sob hospedeiro humano, em relação a quatro temperaturas constantes, $15^{\circ} \mathrm{C}, 20^{\circ} \mathrm{C}, 25^{\circ} \mathrm{C}$ e $30^{\circ} \mathrm{C}$, fotoperíodo de CE 12:12 horas e umidade relativa de $70-85 \%$.

Em relação ao período de pré-oviposição, foram observadas diferenças significativas entre as quatro temperaturas utilizadas, com redução deste período nas temperaturas mais elevadas. Cabe ressaltar, que o período de pré-oviposição é dependente do tempo despendido para a obtenção e digestão da alimentação sanguínea, assim quanto maior o tempo gasto em cada uma destas etapas, maior será o tempo para a postura dos primeiros ovos (Tabela III).

Quanto à oviposição, não foi verificada concordância gonotrófica em A. albopictus, sendo observados dois tipos de comportamento. No primeiro caso, somente após vários repastos sucessivos teve início a oviposição, enquanto no segundo, o repasto era único com a oviposição parcelada, ocorrendo durante dias sucessivos ou em intervalos que compreendiam vários dias. Este último comportamento pode ser considerado como característico da espécie, uma vez que Rozeboom et al. (1973) apontaram, para condições de campo, que o número total de ovos por criadouro é resultado da ação de diferentes fêmeas, as quais depositam a maioria ou todos os ovos maduros ao longo de várias oviposições, que são interrompidas pelo vôo para outros criadouros.

As temperaturas avaliadas afetaram de forma diferenciada a produção de ovos pelas fêmeas, com a temperatura de $15^{\circ} \mathrm{C}$ sendo considerada desfavorável à atividade de oviposição. Nas demais temperaturas, $20^{\circ} \mathrm{C} \mathrm{a} 30^{\circ} \mathrm{C}$, a porcentagem de fêmeas que realizaram a postura foi superior a $80 \%$, com elevadas variações quanto ao número máximo e mínimo de ovos por fêmea (Tabela IV). Sob condições de campo, NevES \& EspínOla (1987) apontam que A. albopictus reproduz-se melhor no verão, e que durante o inverno pode suportar temperaturas de até $13^{\circ} \mathrm{C}$, alcançando melhor desempenho reprodutivo no período do verão.

Diferenças individuais em relação ao total de ovos produzidos por fêmeas de A. albopictus, também foram apontadas por outros autores. GUBLER \& BHATTACHARYA (1971) verificaram que o número de ovos por fêmeas, mantidas a $26^{\circ} \mathrm{C}$, pode variar de 0 a 784 ovos. Em Aedes (Stegomyia) malayensis sob $27^{\circ} \mathrm{C}, 20 \%$ das fêmeas colocam 100 ovos ou menos, $40 \%$ colocam entre 100 e 199 ovos, e apenas 13,3 \% são capazes de colocar entre 610 a 665 ovos durante todo o período de vida (Michael \& Yohannes 1982). Cônsoli et al. (1983) destacam que a fecundidade de Ochlerotatus fluviatilis também varia consideravelmente entre os indivíduos, e se a fecundidade é controlada geneticamente, o alto desvio padrão provavelmente reflete a heterogeneidade da colônia utilizada.

Através da análise de variância, observou-se diferenças significativas no número médio de ovos por fêmea entre as temperaturas de $20^{\circ} \mathrm{C}, 25^{\circ} \mathrm{C}$ e $30^{\circ} \mathrm{C}$, com maior fecundidade a $25^{\circ} \mathrm{C}$. XAvier et al. (1991), observaram que o número médio de ovos por fêmea, alimentadas em hospedeiro humano e mantidas a $25^{\circ} \mathrm{C}$, é de 36,3 ovos, aproximadamente 7,5 vezes menor que a média obtida no presente estudo. Em populações de $A$. albopictus de ambiente silvestre e urbano do Japão, Mogi (1982) obteve média de 15,1 e 80,6 ovos por fêmea, respectivamente. Estas diferenças podem indicar que a origem da população, assim como os procedimentos utilizados nos experimentos, podem determinar alterações na fecundidade das fêmeas.

O número médio de ovos por dia por fêmea foi semelhante nas temperaturas de $25^{\circ} \mathrm{C}$ e $30^{\circ} \mathrm{C}$, no entanto ambas diferiram

Tabela III. Período de pré-oviposição médio, mínimo e máximo (em dias) de Aedes albopictus sob quatro temperaturas constantes, $15^{\circ} \mathrm{C}, 20^{\circ} \mathrm{C}$, $25^{\circ} \mathrm{C}$ e $30^{\circ} \mathrm{C}$, fotoperíodo de CE $12: 12$ horas e umidade relativa de $70-85 \%$.

Período de pré-oviposição em dias

\begin{tabular}{|c|c|c|c|c|}
\hline Temperatura $\left({ }^{\circ} \mathrm{C}\right)$ & Fêmeas (n) & Média (D. P.) & Mín. & Máx. \\
\hline $15^{\circ} \mathrm{C}$ & 1 & $20,00(0,00)^{*}$ & - & - \\
\hline $20^{\circ} \mathrm{C}$ & 35 & $32,05(18,25) \mathrm{a}$ & 10 & 85 \\
\hline $25^{\circ} \mathrm{C}$ & 40 & $12,40(7,81) b$ & 5 & 47 \\
\hline $30^{\circ} \mathrm{C}$ & 33 & $9,93(5,08) \mathrm{b}$ & 5 & 30 \\
\hline
\end{tabular}

* dado excluído da análise de variância

Médias seguidas por letras distintas diferem entre si pelo teste de Tukey- Kramer $(p<0.05)$

D.P.: Desvio Padrão 
Tabela IV. Número médio, mínimo e máximo de ovos obtidos para fêmeas de Aedes albopictus mantidas sob $15^{\circ} \mathrm{C}, 20^{\circ} \mathrm{C}, 25^{\circ} \mathrm{C}$ e $30^{\circ} \mathrm{C}$, fotoperíodo de CE 12:12 horas e umidade relativa de $70-85 \%$.

\begin{tabular}{|c|c|c|c|c|c|c|}
\hline \multirow[b]{2}{*}{$\begin{array}{c}\text { Temperatura } \\
\left({ }^{\circ} \mathrm{C}\right)\end{array}$} & \multicolumn{6}{|c|}{ Número de ovos } \\
\hline & $\begin{array}{l}\text { Fêmeas } \\
(\%) *\end{array}$ & Ovos & Médio (D. P.) & Mín. & Máx. & $\begin{array}{c}\% \text { média de ovos } \\
\text { viáveis }\end{array}$ \\
\hline $15^{\circ} \mathrm{C}$ & $1(2,5 \%)$ & 1 & $1(0)^{* *}$ & - & - & 0 \\
\hline $20^{\circ} \mathrm{C}$ & $35(87,5 \%)$ & 2587 & $73,91(55,72) \mathrm{a}$ & 1 & 221 & $46,08(29,15 \%) \mathrm{a}$ \\
\hline $25^{\circ} \mathrm{C}$ & $40(100 \%)$ & 10795 & $269,87(197,84) b$ & 6 & 752 & $67,36(21,67 \%) b$ \\
\hline $30^{\circ} \mathrm{C}$ & $33(82,5 \%)$ & 6062 & $183,69(135,15) \mathrm{c}$ & 3 & 493 & $67,66(23,50 \%) b$ \\
\hline
\end{tabular}

*porcentagem de fêmeas que ovipuseram em relação ao total de fêmeas testadas

***dado excluído da análise de variância

Média seguidas por letras distintas diferem entre si pelo teste de Tukey- Kramer $(p<0.05)$

D.P.: Desvio Padrão

de $20^{\circ} \mathrm{C}$ que alcançou a menor média. O número de ovos por repasto realizado por fêmea não sofreu variação em relação à temperatura (Tabela V). Estes resultados são semelhantes aos encontrados por Tsuda et al. (1994) para uma população de $A$. albopictus procedente da Tailândia, onde o número de ovos por repasto foi de 28,2 ovos, a $27^{\circ} \mathrm{C}$. Entretanto, estes autores, utilizando a mesma metodologia, verificaram que para populações do Japão o número de ovos produzidos a cada alimentação sanguínea é de 52,2 ovos, indicando que o número de ovos por repasto também pode ser variável de acordo com a origem geográfica da população estudada.

Quanto à viabilidade dos ovos produzidos, nas temperaturas de $25^{\circ} \mathrm{C}$ e $30^{\circ} \mathrm{C}$ foram observadas as maiores porcentagens de ovos viáveis por fêmea, não sendo observadas diferenças significativas entre estas temperaturas (Tabela IV). Segundo ForatTini (1962), a temperatura influencia a fecundação dos ovos de culicídeos, pois em níveis abaixo de $20^{\circ} \mathrm{C}$, é apreciável a porcentagem de ovos inférteis, fato também verificado no presente estudo para a temperatura de $20^{\circ} \mathrm{C}$, na qual aproximadamente $50 \%$ dos ovos apresentaram-se inviáveis.
A previsão do período no qual a densidade populacional de A. albopictus é elevada, deve levar em consideração a faixa de temperatura onde são observadas maior sobrevivência, maior atividade hematofágica, e altas taxas de fertilidade e fecundidade. Tendo em vista o número e a viabilidade de ovos produzidos nos quatro tratamentos, as baixas temperaturas $\left(15^{\circ} \mathrm{C}\right.$ e $20^{\circ} \mathrm{C}$ ) parecem atuar como fator limitante ao crescimento populacional desta espécie sob condições de laboratório. Nesse sentido, observou-se que a fecundidade das fêmeas foi maior na faixa entre $25^{\circ} \mathrm{C} \mathrm{e} 30^{\circ} \mathrm{C}$. Entretanto, as temperatura de $20^{\circ} \mathrm{C}$ e $25^{\circ} \mathrm{C}$ apresentaram-se mais favoráveis à longevidade dos adultos. Apesar de diferentes eventos fisiológicos apresentarem diferentes faixas de temperaturas ótimas, estas informações poderiam ser utilizadas em programas de controle. A eliminação de criadouros artificiais, durante os meses mais frios, pode constituir possível medida para a diminuição do número de fêmeas aptas a procurar fontes de alimentação sanguínea, tendo em vista que as temperaturas encontram-se abaixo do intervalo ótimo para a fase adulta e a maior parte da população encontra-se no estágio imaturo.

Tabela V. Média de ovos por repasto e por dia para fêmeas de Aedes albopictus mantidas sob três temperaturas constantes, $20^{\circ} \mathrm{C}, 25^{\circ} \mathrm{C}$ e $30^{\circ} \mathrm{C}$, fotoperíodo de CE 12:12 horas e umidade relativa de 70-85\%.

Temperatura $\left({ }^{\circ} \mathrm{C}\right)$

$20^{\circ} \mathrm{C}$
$25^{\circ} \mathrm{C}$
$30^{\circ} \mathrm{C}$

Fêmeas

(n)

35
40
33

Média de ovos / dia / fêmea (D. P.)

$1,30(0,99) \mathrm{a}$

$4,20(2,51) \mathrm{b}$

$3,73(2,06) \mathrm{b}$
Média de ovos / repasto / fêmea (D. P.)

Média seguidas por letras distintas diferem entre si pelo teste de Tukey- Kramer $(\mathrm{p}<0.05)$

*n.s.: não significativo ( $<<0.05$ ) (Análise de variância)

D.P.: Desvio Padrão 


\section{REFERÊNCIAS}

Consoli, R. A. G. B.; P. Williams; E. C. Moreno \& B. S. Santos. 1983. Features of reproduction in laboratory reared Aedes fluviatilis (Lutz, 1904) (Diptera: Culicidae). Memórias do Instituto Oswaldo Cruz 78(1): 37-47.

Forattini, O. P. 1962. Entomologia médica. São Paulo, EDUSP, vol. 1, 662 p.

Forattini, O. P. 1986. Identificação de Aedes (Stegomyia) albopictus (Skuse) no Brasil. Revista de Saúde Pública 20: 244-245.

Forattini, O. P. 1996. Culicidologia médica. São Paulo, EDUSP, vol. 1, 548p.

Gomes, A. DE C.; O. P. Forattini; I. Kakitani; G. R. A. M. Marques; C. C. De A. Marques; D. Marucci \& M. De Brito. 1992. Microhabitats de Aedes (Stegomyia) albopictus (Skuse) na região do Vale do Paraíba, Estado de São Paulo, Brasil. Revista de Saúde Pública 26(2): 108-118.

GubleR, D. J. \& N. C. BhatTACHARYA. 1971. Observations on the reproducitve history of Aedes (Stegomyia) albopictus in the laboratory. Mosquito News 31(3): 356-359.

Ibañez-Bernal, S.; B. Briseño; J. P. Mutebi; E. Argot; G. Rodríguez; C. Martínez-Campos; R. Paz; P. De La F. Roman; R. Tapia-Conyer \& A FLISSER. 1997. First record in America of Aedes albopictus naturally infected with dengue virus during the 1995 outbreak at Reynosa, Mexico. Medical Veterinary Entomology 11: 305-309.

Konishi, E. 1989. Culex tritaeniorhynchus and Aedes albopictus (Diptera: Culicidae) as natural vector of Dirofilaria immitis (Spirurida: Filariidae) in Miki City, Japan. Journal of Medical Entomology 26(4):295300 .

Labarthe, N.; M. L. Serrão; Y. F. Melo; S. J. de Oliveira \& R. Lourenço-deOliveira. 1998. Mosquito frequency and feeding habitats in an enzootic canine dirofilariasis area in Niterói, State of Rio de Janeiro, Brazil. Memórias do Instituto Oswaldo Cruz 93(2): 145-154.

Marques, G. R. A. M. \& A. DE C. Gomes. 1997. Comportamento antropofílico de Aedes albopictus (Skuse) (Diptera: Culicidae) na região do Vale do Paraíba, Sudeste do Brasil. Revista de Saúde Pública 31:125-130.

Mitchell, C.; M. Nielbylski; G. Smith; N. Karabatsos; D. Martin; J. P. Mutebi; G. B. Craig \& M. MahleR. 1992. Isolation of Eastearn equine encefalitis from Aedes albopictus in Florida. Science 257:526527.

Michael, T. \& T. Yohannes. 1982. Reproductive biology of Aedes (S.) malayensis (Diptera: Culicidae). Journal of Medical Entomology 19(1):29-33.

MogI, M. 1982. Variation in oviposition, hatch rate and setal morphology in laboratory strains of Aedes albopictus. Mosquito News 42(2): 196-201.

Mori, A. \& Y. Wada. 1977. The gonotrophic cycle of Ae. albopictus in Nagasaki in the field. Tropical Medicine 19: 141-146.

Neves, D. P. \& H. N. Espínola. 1987. Tigre-asiático: outro Aedes nos ameaça. Ciência Hoje 27(5): 82.

RaI, K. S. 1991. Aedes albopictus in the Americas. Annual Review of Entomology 36: 459-484.

Rozeboom, L. E.; L. Rosen \& J. IKeDA. 1973. Observations on oviposition by Aedes (S.) albopictus Skuse and A.(S.) polynesiensis Marks in nature. Journal of Medical Entomology 10(4): 397-399.

Silva, R. F. DA. \& D. P. Neves. 1989. Os mosquitos (Diptera: Culicidae) do Campus Ecológico da UFMG, Belo Horizonte, Minas Gerais. Memórias do Instituto Oswaldo Cruz 84(Supl. IV): 501-503.

Sullivan, M. F.; D. J. Gould \& S. Maneechai. 1971. Observations on the host range and feeding preferences of Aedes albopictus (Skuse). Journal of Medical Entomology 8(6): 713-716.

Tsuda, Y.; M. TAKagi; A. SuzuKi \& Y. WAdA. 1994. A comparative study on life table characteristics of two strains of Aedes albopictus from Japan and Thailand. Tropical Medicine 36(1): 15-20.

Xavier, G. V.; D. P. Neves \& R. F. DA Silva. 1991. Ciclo Biológico do Aedes albopictus (Diptera-Culicidae), em laboratório. Revista Brasileira de Biologia 51(3):647-650. 